\title{
Building better sex robots: Lessons from Feminist Pornography
}

By John Danaher

(Penultimate Draft of a paper due to appear in Al Love You-Developments on Human-Robot Intimate Relations, edited by Yuefang Zhou and Martin Fischer to be published by Springer)

Abstract: How should we react to the development of sexbot technology? Taking their cue from anti-porn feminism, several academic critics lament the development of sexbot technology, arguing that it objectifies and subordinates women, is likely to promote misogynistic attitudes toward sex, and may need to be banned or restricted. In this chapter I argue for an alternative response. Taking my cue from the sex positive 'feminist porn' movement, I argue that the best response to the development of 'bad' sexbots is to make better ones. This will require changes to the content, process and context of sexbot development. Doing so will acknowledge the valuable role that technology can play in human sexuality, and allow us to challenge gendered norms and assumptions about male and female sexual desire. This will not be a panacea to the social problems that could arise from sexbot development, but it offers a more realistic and hopeful vision for the future of this technology in a pluralistic and progressive society.

Key words: Feminism; pornography; sexbots; objectification; commodification; subordination; anti-porn; sex positive feminism

The idea of the sexbot has captured our collective cultural imagination. In the past few years, a spate of films, TV shows, documentaries and newspaper articles have touted the technological possibilities and debated the societal consequences of the rise of the sexbot. Some of this debate has been quite heated. Indeed, there are signs that the sexbot could be the new battleground in our ongoing culture wars around sex and sexuality (Reiss 2006). ${ }^{1}$ For example, in November 2015, the $2^{\text {nd }}$ International Congress on Love and Sex with Robots, which was due to take place in Iskander Malaysia, was abruptly cancelled by its organisers. Islam is the official state

\footnotetext{
${ }^{1}$ Note I use the term 'culture war' to refer to a set of debates that are located around common themes concerning restrictive vs pluralistic views of sex and sexuality. For more on this phenomenon see Reiss 2006.
} 
religion in Malaysia and the authorities there expressed opposition to the conference. The Inspector General of Police - Khalid Abu Bakar - said that there was nothing 'scientific' about the topic and that sex between humans and robots was 'illegal in Malaysia' (Reese 2015). This did not deter the organisers, who decided to host the congress at Goldsmith's University London instead. Buoyed by its success, they decided to host a third Congress in Goldsmith's in December of 2017. But the venue had to be changed due to 'credible threats...by Muslim extremists' (Hill 2017).

It's not just religious extremists who find the idea of sex between humans and robots problematic. Certain strands of feminism find it problematic too. The most vocal exemplar of this is Kathleen Richardson, a Professor of the Ethics and Culture of Al at De Montfort University, Leicester. In September of 2015, she launched the Campaign Against Sex Robots, ${ }^{2}$ arguing that we ought to oppose the development of this technology because it will encourage humans (specifically men) to treat other humans (specifically women) in an objectified and commodified way.

This is not the first time that religious extremists and (certain) feminists have found common cause on the matter of sexual propriety. We've been here before. In the 1980s and early 1990s, the radical feminists Catharine MacKinnon and Andrea Dworkin waged war against pornography, and in the mid-2000s a new cohort of antiporn feminists came to prominence decrying the particular harms caused by the abundance of pornography available via the internet. These anti-porn feminists have forged uneasy alliances with conservative religious groups in the past, adopting many of their tropes and tactics in an attempt to rescue people from a pornified culture (Smith and Atwood 2012). But these thinkers and activists have always been resisted from within feminism itself, with many arguing that there is a space for sexpositive, female-friendly pornography that does not stereotype or restrict female sexual pleasure (Taormino et al 2012; Davies 2017; Moreland 2015).

Is there anything to be learned from the history of the porn wars for the emerging sexbot wars? In particular, is there a way for feminists to embrace the creation of sexbots just as (some) have embraced the creation of pornography in the past? I think there is. I will make this case by first considering the ways in which antisexbot feminism is influenced by the arguments of anti-porn feminism, and then by showing how it could be influenced by the arguments of sex positive feminism.

\section{The Arguments of Anti-Porn Feminism}

2 See https://campaignagainstsexrobots.org (accessed 30/6/2018) 
Those who have watched mainstream heterosexual pornography cannot help but notice its repetitive content and style. It is filmed from the 'male gaze'. Women are presented as sexual objects - playthings to be subordinated for male pleasure. They are penetrated from all angles, beaten, choked and ejaculated upon. Even if viewers are sexually stimulated by this content, they may worry about the moral propriety of this stimulation. What does it say about their sexual psyches? If they are particularly conscientious, they may even worry about the lives and experiences of the performers. Did they really consent to being depicted in this way? Do they need to be 'saved' from the industry?

Anti-porn feminism is grounded in concerns of this sort. Starting in 1970s and 1980s, and continuing through the present day, a vocal strand of feminist thought has always maintained a steadfast opposition to the depictions of women in pornography. The most well-known proponents of this view were Catharine Mackinnon and Andrea Dworkin (MacKinnon 1996). MacKinnon was (and still is) a prominent feminist legal scholar, responsible for a number of significant interventions in the areas of sexual harassment and rape. Dworkin was a feminist author and campaigner. Sharing a common concern about the misogynistic content of mainstream pornography, MacKinnon and Dworkin sought practical legal reforms that could address the problem in a way that empowered ordinary women. This meant avoiding the classic legal solution to the problem of pornography: state censorship. The state, after all, was a manifestation of the patriarchy. So they tried something else. They drafted a civil rights ordinance that would enable women to sue for the harm caused to them - as a collective - by the production and distribution of pornography. They travelled throughout the United States trying to get these ordinances on the statute books.

MacKinnon and Dworkin generated much heat, but little light through their efforts. More mainstream, liberal scholars argued that pornography fell under free speech protections and MacKinnon's civil rights ordinances were never upheld in court. This did not end the opposition to pornography. Other scholars took up MacKinnon's baton, trying to craft more philosophically sophisticated and rigorous defences of her views, and integrating them into liberal strands of feminist thought. Furthermore, in the early 2000s, once the pornographic potential of the internet became more apparent, a new movement of anti-porn feminism arose. Spearheaded by the likes of Gail Dines (2010) and Melissa Tankard Reist (2011), this movement drew distinctions between the 'old' and 'new' worlds of pornography. Indeed, some of its leaders have an almost nostalgic view of pornography from the 1950s and 1960s. Dines, for instance, has argued that internet-based porn is 'not your father's 
Playboy' and that there is something far more disturbing about it in terms of its accessibility and extremeness (Smith and Attwood 2012). This new wave of anti-porn feminism has continued to the present day, with several prominent male conservatives also trying to highlight the harms of internet-based porn (Shapiro 2013)

What is the intellectual basis for anti-porn feminism? It is difficult to distill 30plus years of scholarship into a handful of simply formulated arguments particularly since these arguments have been refined and elaborated in response to criticism over the years. Nevertheless, some simplification is possible. All anti-porn feminists think that porn is harmful to women and contrary to the goal of gender equality. Some are particularly concerned about what happens to the women who appear in pornographic material. Famously, Linda Lovelace, the star of the infamous Deep Throat film brought allegations of abuse and rape against the film's producer (her husband at the time) years after its release (Lovelace and McGrady 1980). She is not alone. Allegations of this sort are not uncommon in the porn-world (or, as we are now learning in the wake of the Harvey Weinstein scandal, in mainstream Hollywood).

Notwithstanding the importance of this issue, most anti-porn feminists focus their opposition on the harm to women who are not directly involved in the production of pornography. They differ in how they characterise and understand that harm. Most view the harm in collective terms, i.e. as something that accrues to all women as a social class not just (or necessarily) to individual women. Some view the harm as intrinsic to the production and distribution of porn, i.e. they think that pornography, in and of itself, constitutes a kind of harm to women. Some view the harm in more instrumental or causal terms, i.e. they think that pornography causes harm to women due to the effects of repeated exposure.

Those who favour the instrumental view find themselves embroiled in the 'effects' debate. This is the ongoing empirical debate about the effects of exposure to pornography on 'real world' behaviour. The standard anti-porn claim is that exposure to hardcore pornography normalises misogynistic attitudes among its consumers and encourages them to act in sexually violent ways. This claim is hotly contested. There is no shortage of studies done on the effects of pornography, but there are conflicting results and considerable controversy about the direction and strength of the causal link (for reviews of the empirical literature see Danaher 2017a and 2017b). The existence of such controversy has led many anti-porn feminists to develop alternative, more 'sophisticated' theories concerning the causal link 
between pornography and real-world behaviour (Eaton 2007), or to simply sidestep the debate altogether.

That's effectively what MacKinnon and Dworkin did in their campaign. Mackinnon (1996), in particular, articulated one of the most influential critiques of the intrinsic harm of pornography. She argued that pornography constituted, and not merely caused, harm to women. Specifically, she argued that pornography silenced and subordinated women as a class. Pornography depicted women in objectified, commodified and dehumanised forms. It thus communicated the view that women's consent, autonomy and pleasure are not to be taken seriously in sexual interactions. This communicated content was what silenced and subordinated women. The more recent anti-porn feminists have argued that the objectification, commodification and dehumanisation of women through pornography has been exacerbated by the internet (Smith and Attwood 2012). On porn websites, pornographic scenes are edited and remixed into short clips and compilations of particular sexual acts. This 'unbundling' of pornographic content from any pretense of narrative or moviemaking, speeds up the commodification process.

Of course, it is a little difficult to see how the MacKinnon-style claim differs from the 'effects'-claim. Surely what MacKinnon was arguing was that pornography has the effect of silencing and subordinating women, not that it amounts to the silencing and subordination of women? But no, this was not what she was trying to argue. Other feminist scholars such as Rae Langton (1993) and Mary Kate McGowan (2004) have tried to make sense of MacKinnon's arguments by relying on the tools of speech act theory. First defended by the philosopher JL Austin, speech act theory starts from the simple observation that speech (defined broadly to include words and images) doesn't merely report on how the world is; it also does things to the world, particularly the social world. When a judge declares that someone is guilty, she is not simply reporting a fact; she is saying something that alters the legal status of that person. The position defended by Langton and McGowan is that pornography is not merely a depiction of women; it is doing something to women through its depictions. Their arguments are complex, and McGowan in particular is cagey about their ultimate persuasiveness, but in essence they both argue that pornography has a kind of social authority (similar to that of the judge) that allows it to establish the norms for sexual engagement. Due to the content of pornography, the norms it establishes are ones that serve to silence and subordinate women.

This may be a little difficult to wrap your head around. Does pornography really have that kind of social authority? Should we think of pornography as a kind of 
speech? Some anti-porn feminists lament the equation of pornography with speech. For example, Joan Mason-Grant (2008) argues that we should view porn as an 'embodied practice', something that is produced and consumed through 'embodied enactments' and that habituates us to a particular style of behaviour. This may be a more plausible view, but MacKinnon's use of the 'speech' paradigm was deliberate and strategic. She was fully aware that defenders of pornography would try to use free speech principles to protect what they were doing. She was trying to undercut them by arguing that pornography was not ordinary speech. It was a harmful speech act.

The nuances of these arguments are fascinating in their own right, but we would be detained excessively by considering them. The question before us is whether these anti-porn arguments carry over into the debate about sex robots. Do we see similar arguments and ideas being adopted? Indeed we do.

\section{The Arguments of Anti-Sexbot Feminism}

Although sex robots have long been an object of literary and cultural imagination, their technical feasibility has only become apparent in recent years. Sex dolls, of course, have been with us for some time. The classic origin story tells us that they were invented by Dutch sailors in the 1700s (hence the still common name for sex dolls of 'Dutch Wives' in certain parts of the world). But sex dolls are just inanimate, unintelligent mannequins that can be manipulated by their users for sexual pleasure. The possibility of a sex robot, one that can move and react intelligently to its user, is only now becoming a reality. A handful of companies are racing to create the world's first fully functional sexbot - something that will provide a realistic facsimile of human-to-human sexual contact (Owsianik 2017). Given other advances in robotics and artificial intelligence, it is only a matter of time before these sophisticated and fully functional sexbots become more widely available.

This has provoked a handful of scholars to wonder about the social and ethical consequences of this development. A burgeoning literature is now emerging, with numerous peer-reviewed articles on the topic, and several books published or due to be published (Devlin 2018; Richardson 2018; Danaher and McArthur 2017; Cheok and Levy 2018; and Cheok, Devlin and Levy 2017). Within this literature there is a small but noticeable strand of anti-sexbot feminism that follows the anti-porn playbook. This anti-sexbot feminism starts from the observation that the current projects aimed at developing sexbots are, in the main, trying to create sexbots that 
look like women and cater to a largely male customer base. This is undoubtedly true. Although companies like TrueCompanion and Abyss Creations do create male sexbots, this is clearly a secondary market. For example TrueCompanion - who may or may not have ever sold or produced a functional sex robot ${ }^{3}-$ don't provide $^{\prime}$ images of their male model on their website, but have demoed a physical version of their female model. And Abyss Creations makers of the world's most realistic sex dolls (Real Dolls), and now creating sex robots (RealBotix) focus predominantly on female models, even though they have now created a male model. Furthermore, Abyss Creations make dolls/robots of a very particular body-shape and type. They typically make dolls that recreate the 'porn-star' look, i.e. large-breasted and thinwaisted. Matt McMullen, founder of Abyss Creations, does make custom dolls that appeal to a more diverse set of tastes, but these are in the minority (and customers pay a premium price for the bespoke service). Furthermore, the conversational style of the available sex robots - based on YouTube videos uploaded by their creators ${ }^{4}$ - seems to follow a typical 'porn-type' script and make assumptions about the type of behaviour that men desire in women. ${ }^{5}$

Starting from these observations, anti-sexbot feminists then develop their arguments on a common template. On previous occasions, I have referred to this as the 'symbolic-consequences' template because it works from the claim that there is something symbolically harmful about the production, design and behaviour of sexbots, to the claim that this will have harmful consequences for society (Danaher 2017b). In other words, the arguments of anti-sexbot feminists typically blend together the intrinsic and instrumental arguments of anti-porn feminists.

The aforementioned Kathleen Richardson is undoubtedly the strongest proponent of anti-sexbot feminism - the Catharine MacKinnon of the robot age. Along with her colleague Erik Brilling, she launched the Campaign Against Sex Robots in September 2015. She set out the campaign's main arguments in a position paper, which she has expanded in a series of talks and debates, and is currently developing

3 The status of TrueCompanion's robot is doubted by some. David Levy (2013) has expressed significant doubts. For an overview of the controversy, see Gray (2015)

${ }^{4}$ For an example, see the conversation depicted in the promotional video for Synthea Amatus's sex robot Samantha, available at https://www.youtube.com/watch?v=0FHzg3T3yrw (accessed 30/6/2018). It should be noted, however, that the maker of Samantha (Dr. Sergio Santos) is aware of some of the feminist critiques and intends to add features - such as the capacity of Samantha to say „no' to sex - in order to address these concerns. For more on this see Santos and Vasquez 2017.

${ }^{5}$ For more on the importance of this, see Bendel 2017 
into book-length treatment (Richardson 2015 \& 2018). The essence of her view is very straightforward. She worries about the modern tendency to objectify and commodify the human body. She thinks it is ethically problematic to view one's own body and the bodies of others as 'things' that can be alienated from the self and bought and sold on a market. She sees a general trend towards such commodification in neo-liberal, capitalistic societies, and views it as particular problem for women who are bought and sold on sex markets. She thinks that the development of sexbots exacerbates and speeds up this trend. In fact, she argues that the sexbot represents the ultimate objectification and commodification of the female body. The goal of sexbot advocates like David Levy - author of one the ground-breaking works on the topic Love and Sex with Robots (2007) - is to recreate a prostitute-john style relationship in robot form. Richardson thinks this will normalise the view of women's bodies as 'things' to be manipulated and sold for sexual pleasure:

'...by drawing on prostitution as the model for human-robot sexual relations, Levy shows that the sellers of sex are seen by the buyers of sex as things and not recognised as human subjects. This legitimates a dangerous mode of existence where humans can move about in relations with other humans but not recognise them as human subjects in their own right.'

(Richardson 2015, 290)

Richardson makes strong claims about the causal effects of interacting with sexbots. Drawing on analogies with prostitution, pornography and sex toys, she argues that there is no reason to think that the widespread availability of sexbots will somehow sate the desire for objectified sexual relations (and thereby reduce harm to 'real world' women). On the contrary, she argues that there is reason to suspect that it will heighten such desire.

A similar, though more moderate, set of anti-sexbot arguments can be found in a paper written by the Canadian-lawyer Sinziana Gutiu. Titled 'The Roboticization of Consent', and clearly influenced by the work of anti-porn feminism, the paper argues that there is something deeply disturbing about the representational properties of sexbots. They recreate women as passive, ever-consenting sexual tools, which will contribute to their silencing and subordination, and will normalise a 'rape culture':

To the user, the sex robot looks and feels like a real woman who is programmed into submission and which functions as a tool for sexual purposes. The sex robot is an ever-consenting sexual partner and the user has full control of the robot and 
the sexual interaction. By circumventing any need for consent, sex robots eliminate the need for communication, mutual respect, and compromise in the sexual relationship. The use of sex robots results in the dehumanization of sex and intimacy by allowing users to physically act out rape fantasies and confirm rape myths.

(Gutiu 2012, 2)

The argumentative style here is very similar to that of MacKinnon, and Gutiu even proposes a similar legal solution to the problem of sexbots. She is not comfortable with the idea of a total ban on sexbots because she thinks there are competing values at play (freedom of expression; the need to encourage innovation; and the need for empirical research on human sexuality) that ought to be balanced against the good of limiting sex robots. Nevertheless, she thinks that private legal remedies should be made available to women who are harmed as a result of their proliferation.

Both Richardson and Gutiu are much stronger on the likely effects of sexbot usage than many contributors to the anti-porn literature. But there are some antisexbot arguments that focus purely on the intrinsic/symbolic harms of sexbots. Robert Sparrow has developed one such argument in a paper entitled 'Robots, Rape and Representation' (Sparrow 2017). His argument focuses on robots that facilitate rape fantasies by communicating a refusal to consent. Though Sparrow confesses to being a fan of the claim that sexbots will cause users to act out in problematic ways, he concedes that this may be difficult to prove. So he focuses instead on the expressive and representational harms involved in designing robots that facilitate rape fantasies. He says that the use of such robots would be problematic because it (a) would express disrespect for women (a speech act style argument) and (b) demonstrate a significant character defect on the part of the user.

These anti-sexbot arguments can certainly be criticised. Although I have myself defended something similar to Sparrow's argument in relation to child sexbots and rape-bots (Danaher 2017a), I am nonetheless very wary of arguments that make robust claims about the likely effects of sexbots on behaviour due to the great empirical controversies in other 'effects' debates; furthermore, I think that the symbolic meaning and character of sexbots is more contingent and reformable than critics suppose and that trying to ban or limit the production of sexbots is unlikely to be effective (Danaher 2017b). I think a better strategy is to change how we think about and ultimately create the technology. This is where the history of sex positive feminism can prove instructive. 


\section{The Case for Feminist Pornography}

Anti-porn feminism has always been resisted from within feminism itself. As soon as MacKinnon and Dworkin started to market their anti-porn wares, a cohort of sex positive feminists were quick to respond. These sex positive feminists argued that anti-porn feminism, in its desire to rid the world of misogynistic content, overlooked the positive role that pornography can play in female sexuality. To state the obvious: sex is a human good, and women can and do enjoy sex as much (if not more) than men. Women like to explore the boundaries of their sexuality; many women find that pornographic content enables them to do this; and at least some women find that producing, distributing and participating in porn has a positive role in their lives.

You don't have to go far to find evidence of this. Books such as The Feminist Porn Book (Taormino et al 2013), Coming Out Like a Porn Star (Lee 2015), and Pornography Feminism: As Powerful as She Wants to Be (Moreland 2015), are filled with testimony from female (and male, transgender and genderqueer) pornstars who feel empowered by their participation in pornography. Consider the testimony of Dylan Ryan:

My initial ideals about my role in porn slowly transformed into what I actually did in porn. Porn has been a positive choice for me. It is no longer something I think will be good for me, it is something I can say has been empowering and strengthening rather than oppressive and denigrating.

(Taormino et al 2013, 128)

Or Lorelei Lee:

What I can tell you is that as I continued to do this work - as I came up against my own ideas about femininity, power and sex - I found strength in the part of my identity that developed out of my experiences as a sex worker. I found a manifesto of my own ethics, and I found that, to my surprise, I believe deeply in the positive power of sexually explicit imagery.

(Taormino et al 2013, 200)

Or Nina Hartley:

[B]eyond providing a perfect playground for my hedonistic indulgences, I saw and continue to see porn as a means by which to share my deeply held ideas and 
opinions about sex, pleasure, love, and intimacy with other like-minded folks.

(Taormino et al 2013, 230)

It is hard to argue that these women are participating in their own silencing and subordination, Indeed, it seems like they are doing the exact opposite (at least by their own lights). As Alex Davies notes, the existence of such female pornographers poses a dilemma for anti-porn feminists (Davies 2017). The typical response from the anti-porn feminists is to completely ignore them or suggest that they are victims of false consciousness (i.e. that their expressions of their own sexual desires and preferences are not truly authentic or genuine). But this is a difficult case to make. It's hard to read the testimony of someone like Nina Hartley and think that she is not expressing her authentic self. What's more, you get the sneaking suspicion that no expression of female sexual desire could ever be authentic enough to please the anti-porn school of thought. For example, Jane Ward, professor of Women's Studies at UC Riverside, recounts the time she attended a talk by Ariel Levy, author of the book Female Chauvinist Pigs (Levy 2005). In the book, Levy criticises 'raunch culture' and argues that women who enthusiastically participate in it are not sexually liberated or providing an authentic expression of their sexuality. Ward wondered what an authentic expression of female sexuality should look like and asked Levy about this after her talk:

At this point, I asked her pointedly, "what do you want women to find sexy?" She laughed and responded that it wasn't for her to say. "But isn't that what's at stake here?" I asked.

(Taormino et al 2013, p 134)

According to sex positive feminism, it is, indeed, what is at stake. Unless we completely suppress or deny female sexuality, women can and will find things sexy, and pornography can and will play a role in helping them to figure this out. This is not to say that sex positive feminists think that there are no problems with the depiction of women in mainstream pornography, or that it always has a positive influence on their lives. It is, rather, to say that they think the solution to bad porn is simply to make better porn - in short: to make 'feminist pornography'.

What does this entail? According to the Toronto-based feminist sex shop Good for Her, in order for a pornographic work to count for the purposes of the Feminist Porn Awards: 
"a woman must have been involved in the production, writing or direction of the work; or the work must convey genuine female pleasure; or the piece must expand the boundaries of sexual representation and challenge mainstream porn stereotypes."

(Weber 2013)

This corresponds, roughly, to how feminist pornography has been pursued in academic and practical circles. There are, in essence, three schools of thought on how to create truly feminist pornography: (i) the content school; (ii) the procedural school; and (iii) the contextual school.

The content school focuses on the actual representations and depictions of women in pornography. It believes that in order to make truly feminist pornography you have to change the content of porn: provide more realistic depictions of female sexuality and make it appeal more to women. One of the pioneers in this field was Candida Royalle (2013). She was one of the first women to direct and produce pornographic films. With her business partner, Lauren Neimi, she founded a production company called Femme Productions that focused on making porn that bucked the conventions of mainstream porn. They depicted explicit sex scenes that weren't overly focused on genital closeups, that didn't end in 'money shots' (i.e. with the male performer ejaculating on the face of the female performer), that had closeups of people's faces while climaxing, and that focused, generally, on tenderness, connectedness and sensuality. They also tried to depict women of all ages and types, and to shoot their films in a cinema vérité style. In short, the guiding ethos of their approach was to avoid the objectification, domination and subordination of women that is common in mainstream pornography.

This remains a popular way in which to create feminist porn. But it has its critics. Some women claim to be attracted to more objectifying forms of pornography, and enjoy playing with fantasies of subordination and domination in their sex lives (Davies 2017). Academic critics also worry that the content approach pigeonholes and stereotypes female sexual desire. The danger with the content school is that it assumes that there is a certain type of porn that interests women and another type that interests men. For those feminists who wish to challenge the gender binary, this does not sit well (Devlin 2015).

This is one reason why the procedural and contextual schools of thought have 
arisen. Instead of focusing specifically on the content, proponents of these approaches think that we should focus on the procedures through which pornography is produced and the contexts in which it is consumed. Tristan Taormino (2013) is a proponent of the procedural approach and adopts an ethical charter for the creation of her own pornographic films. She has long discussions with the performers about their sexual preferences and desires (often forming part of the films themselves); and she includes them in all decisions about what is going to be shot and who they will be performing with. She wants the performers to create their own preferred representations, and not necessarily conform to some predefined script or ideal, though there is a balance to be struck here and she does also care about representing female desires and preferences. Academics like Lynn Comella (2017) and Matt Drabek (2016) are proponents of the contextual approach, arguing that what ultimately matters are the contexts in which porn are distributed and consumed. Provided this is done in the right social environment, in a thoughtful manner that includes women's voices and perspectives, and takes seriously broader concerns about gender equality, it is possible for even extremely objectifying pornography to count as feminist.

To be clear, although the feminist approach to pornography tries to ensure that the female perspective and voice is included in porn, it is not simply about appealing to female consumers. The goal is also to produce porn that will appeal to men and challenge stereotyped conceptions about the distinction between male and female sexual desire. Thus, men can and should be involved in the feminist porn project.

\section{The Possibility of Feminist Sex Robots}

I think the insights of the feminist porn movement provide the basis for a positive reframing of the sex robot debate, and reimagining of the project to create sex robots. While anti-sexbot arguments raise some important concerns about how women (in particular) are being represented in robotic form, the response to this should not be to ban or limit the creation of sexbots, but simply to make better sexbots - i.e. to make 'feminist sexbots'. The label may not appeal to everyone but the project itself has much to recommend it. It can help us to reimagine what it means to create a sexbot, to think about how such robots could help men and women explore the boundaries of their sexuality, and to consider how such robots could complement and enhance (rather than replace) human-to-human relationships. We don't need to deny or repress this new development in human sexual expression; we can simply try to make it more sex positive. 
The project can take its cue from the three main schools of thought in feminist pornography. We can work to ensure better content (i.e. depictions or representations of female (and male) sexuality in robotic form); better processes (i.e. more female voices included in the production and distribution of sexbots); and better contexts (i.e. social environments and conversations surrounding the consumption and use of sexbots).

In terms of content, there is clearly work to be done. There is a need for greater diversity in the forms that sexbots take, and the behavioural scripts (be they learned or not) that they follow. To insist on creating sexbots that adopt the 'porn-star' look, and that use unsophisticated ways of expressing sexual desire and interest, shows a lack of imagination when it comes to the possibilities inherent in this technology. Creating robots that are more realistic in their representations (both physical and behavioural) of women, that represent men, and that perhaps challenge the gender binary could be a valuable part of the feminist project around sex and sexuality. Indeed, Kate Devlin, one of the clearest voices on this topic, has argued that we should move beyond 'human-likeness' as the gold-standard when it comes to the design and function of a sexbot. She argues that there could be new forms and modalities of sexual experience to be discovered if we let our imaginations roam free (Devlin 2015).

But we must also recall the lessons of the feminist porn movement and realise that it is not all about content and form. Ensuring better processes of production and contexts of consumption is probably even more important. This means making sure that the female perspective and voice is not overlooked or ignored, but is rather included and incorporated into the design and distribution of sexbots. This can help ensure a more positive set of representations, and a more positive role for sexbots in exploring the boundaries of human sexuality. Fortunately, there are indications to suggest that this is already happening, particularly if we move beyond sexbots per se and consider the broader sextech industry. Although still dominated by men, and often facing severe limitations on how it can be funded, the sextech industry is home to a number of prominent and progressive female voices (Bevan 2016). Cindy Gallup and Stephanie Alys are two such voices. Gallup is the founder of the website 'makelovenotporn', which provides alternative pornographic content and has recently created a fund for female-led sextech (Evans 2017). Alys is the founder of the company MysteryVibe, whose flagship product is a flexible, 'smart', vibrator. She has spoken frequently about the proper role for the sextech industry. She argues that it should not try to market tech as a 'solution' to some sexual problem the user may be having, but rather as something that can enhance subjective pleasure, 
facilitate connection, and aid sexual discovery (Alys 2016). She sees the cultural fascination around sexbots in a positive light because when confronted with such objects most people do not ask questions about their features and functionality. Instead, they ask deeper philosophical questions about how these robots relate to us (and how they make us feel), and can prompt research and development that furthers our understanding of relatedness and sexuality. This can help reorient the conversation around technology and sex.

There are also voices within academia that provide a more positive context for the design and distribution of sex robots. Julie Carpenter (2017) and Kate Devlin (2015 \& 2018) are pioneers in this regard. Carpenter is a psychologist/anthropologist who has done extensive work on human-machine interactions, and written about the new forms of intimacy and sexuality that may be possible with robots. Devlin is a computer scientist at Goldsmith's University and founder of the annual UK Sextech Hackathon. Writing in response to Kathleen Richardson's Campaign Against Sex Robots, Devlin has acknowledged problems with the gendered stereotypes inherent in the current crop of sexbots, but argues that our response to this should not be to 'import established prudishness' into the development of this technology. Instead, we should see sex robotics as something that 'allows us to explore issues without the restrictions of being human', and we should look upon the machine as a 'blank slate that offers us the chance to reframe our ideas' (Devlin 2015).

These voices provide a seedbed from which an appropriate context for a feminist sexbot project can emerge, but they are only the beginning. Much more is needed in this regard, including contributions from empirical researchers on how to optimize the positive impact of this technology. Some may be skeptical and argue that advocating for such a project, however well-intentioned, is naïve given that there may be no market for this kind of technology. People may want the stereotyped, misogynistic models. Indeed, isn't that the real lesson from the world of pornography? Feminist porn has grown over the years but it has not succeeded in radically reforming mainstream pornography. It exists alongside it and appeals to a niche audience.

I agree that we should not be naïve about the prospects for success. Still, the fact that feminist porn has emerged and continues to develop and thrive should provide some grounds for optimism (along with other positive developments in society around gender equality and the awareness of misogyny and sexual harassment). Furthermore, there may be some grounds for greater optimism with regard to sexbots. Feminist porn arose as a response to an already well-established field of 
mainstream hardcore porn. When it comes to sexbots, the cultural conversation is well ahead of the technology. There is, consequently, an opportunity to incorporate the female perspective into the technological project before it becomes wellestablished.

\section{Conclusion}

To use the now clichéd phrase: sexbots are coming. If the anti-sexbot feminists are right, this is something to lament and oppose. They will distort our sexual psyches and exacerbate misogyny and subordination. There is reason to doubt that this will be the case, but even if it is correct, it's not clear that the best response is to simply ban or limit their creation. We should learn from the history of the feminist porn wars and from the arguments of feminist pornographers. There could be a sex positive, feminist-friendly role, for sexbots if we can ensure the right content, process and context for their creation. This is not going to be a panacea. It will not necessarily resolve the deep-seated origins of the culture wars around sex and sexuality. Those wars are rooted in fundamental views about societal values and norms (Reiss 2006). Those who favour traditional, conservative and restrictive social norms will remain suspicious of and resistant to the technology of sex; and reversing centuries (millennia) of gender inequality and sexism is going to take more than a positive sex robot project. But given the reality of sexual diversity and pluralism, and the long-standing role that technology has the expression of human sexuality, the traditional view seems doomed to disappointment. For those of us committed to a more positive and progressive vision of our sexual futures, reimagining the sex robot project along the lines suggested in this article seems like the best way forward.

\section{Acknowledgements}

The author would like to thank Yuefang Zhou, Brian Earp, Sven Nyholm and two anonymous reviewers for feedback on earlier drafts of this paper.

\section{References}

Alys, S. (2016). When Robots get X-Rated: Al, Big Data and the Future of SexTech, talk at Slush 2016, available at http://www.slush.org/video/robots-get-X-rated-aibig-data-future-sextech/ 
Bendel. O. SSML for Sex Robots. In: Cheok, A. D.; Levy, D. (Hrsg.). Love and Sex with Robots. Third International Conference, LSR 2017, London, UK, December 19-20, 2017, Revised Selected Papers. Springer International Publishing, Cham 2018. pp. 1 - 11.

Bevan, K. (2016). The Women Taking Back the Porn Industry and Moving Sextech from Boardrooms to Bedrooms. Wired Magazine 2 September 2016, available at http://www.wired.co.uk/article/sextech-trends-female

Carpenter, J. (2017). Deus Sex Machina: Loving Robot Sex Workers and the Allure of an Insincere Kiss. In Danaher, J. and McArthur, N. (eds). Robot Sex: Social and Ethical Implications. Cambridge, MA: MIT Press.

Cheok, A. D.; Levy, D. (Hrsg.). Love and Sex with Robots. Third International Conference, LSR 2017, London, UK, December 19-20, 2017, Revised Selected Papers. Springer International Publishing, Cham 2018.

Cheok, A. D.; Devlin, K.; Levy, D. (Hrsg.). Love and Sex with Robots. Second International Conference, LSR 2016, London, UK, December 19-20, 2016, Revised Selected Papers. Springer International Publishing, Cham 2017. They contain also ethical contributions.

Comella, L. (2017) Vibrator Nation: How Feminist Sex Toy Stores Changed the Business of Pleasure. Durham, NC: Duke University Press

Danaher, J. (2017a). Robotic Rape and Robotic Child Sexual Abuse: Should they be criminalized? Criminal Law and Philosophy 11(1): 71-95

Danaher, J. (2017b). The Symbolic-Consequences Argument in the Sex Robot Debate. In Danaher, J. and McArthur, N. (eds). Robot Sex: Social and Ethical Implications. Cambridge, MA: MIT Press.

Danaher, J. and McArthur, N. (eds) (2017). Robot Sex: Social and Ethical Implications. Cambridge, MA: MIT Press 2017).

Davies, A. (2017). A Liberal Antiporn Feminism? Social Theory and Practice, forthcoming, available at https://www.academia.edu/35112280/A_liberal_antiporn_feminism_forthcoming_in_Social_Theory_and_Practice_ 
Devlin, K. (2015). In Defence of Sex Machines: Why Trying to Ban Sex Robots is wrong. The Conversation 17 September 2015, available at https://theconversation.com/in-defence-of-sex-machines-why-trying-to-ban-sexrobots-is-wrong-47641

Devlin, K. (2018). Turned On: Science, Sex and Robots. London: Bloomsbury Press.

Dines, G. (2010). Pornland: How Porn Has Hijacked Our Sexuality. Boston: Beacon Press.

Drabek, M. (2016) Pornographic subordination, power, and feminist

alternatives. Feminist Philosophy Quarterly 2 (1): article 2.

http://ir.lib.uwo.ca/fpq/vol2/iss1/2. doi:10.5206/fpq/2016.1.2.

Eaton, AW (2007). Towards a Sensible Anti-Porn feminism. Ethics 117: 674-715

Evans, J. (2017). Sex, the Final Frontier: Cindy Gallop raises $\$ 2 M$ from mysterious investor for social sex tech. TechCrunch 21 Jan 2018. Available at https://techcrunch.com/2018/01/21/sex-the-final-frontier-cindy-gallop-raises-2mfrom-mysterious-investor-for-social-sex-tech/

Gray, H. (2015). Roxxxy and Beyond: A Look at the Present and Future of Sex Robots. Future of Sex, 25 August 2015 - available at https://futureofsex.net/robots/roxxxy-and-beyond-a-look-at-the-present-andfuture-of-sex-robot/ (accessed 30/6/2018)

Gutiu, S. "Sex Robots and the Roboticization of Consent," We Robot Law Conference Miami (2012), robots.law.miami.edu/wpcontent/uploads/2012/01/GutiuRoboticization_of_Consent.pdf

Hill, R. (2017). Sex robot forum venue 'encrypted in a poem'. The Register 19 December 2017, available at https://www.theregister.co.uk/2017/12/19/intimate_robot_conference_bizarre L

Langton, R. (1993). Speech Acts and Unspeakable Acts. Philosophy and Public Affairs 22: 293-330. 
Lee, J. (2015). Coming Out Like a Porn Star. Los Angeles, CA: Threel Media

Levy, A. (2005). Female Chauvinist Pigs: Women and the Rise of Raunch Culture. New York, NY: Free Press.

Levy, D. (2013). Roxxxy the Sex Robot - Real or Fake?. Lovotics 1: 1-4 - available at https://futureofsex.net/wp-content/uploads/2015/08/David-Levy-Roxxxy.pdf (accessed 30/6/2018)

Lovelace, L and McGrady, M. (1980). Ordeal. New York, NY: Citadel Press.

MacKinnon, C. (1996) Only Words. Cambridge, MA: Harvard University Press.

Mason-Grant, J. (2008). Pornography as Embodied Practice. In Soble, A. and Power, N. (eds) Philosophy of Sex: Contemporary Readings. Lanham, MY: Rowman and Littlefield.

McGowan, M.K. (2003). Conversational Exercitives and the Force of Pornography. Philosophy and Public Affairs 31(2): 155-189.

Moreland, R. (2015). Pornography Feminism: As Powerful as She Wants to Be. Arlesford, UK: Zero Books.

Owsianik, J. (2017) 'State of the Sex Robots: These are the companies trying to create robotic lovers'. Futureofsex.net 16 November 2017 -

https://futureofsex.net/robots/state-sex-robots-companies-developing-roboticlovers/

Reese, H. (2015). Academic conference on 'Love and Sex with Robots' abruptly cancelled after being declared illegal. Tech Republic 21 October 2015, available at https://www.techrepublic.com/article/academic-conference-on-love-and-sexwith-robots-abruptly-cancelled-after-being-declared-illegal/

Reiss, I. (2006). An Insider's View of Sexual Science since Kinsey. Lanham, Md.: Rowman and Littlefield. 
Richardson, K. (2015). The 'Asymmetrical' Relationship: Parallels Between Prostitution and the Development of Sex Robots. SIGCAS Computers \& Society 4, no. 3 (September 2015): 290-293

Richardson, K. (2018). Sex Robots: The End of Love. London: Polity Press.

Royalle, C. (2013). "What's a nice girl like you..." in Taormino et al (eds) The Feminist Porn Book: The Politics of Producing Pleasure. New York: The Feminist Press at CUNY.

Santos, S. and Vazquez, J. (2017). The Samantha Project: a Modular Architecture for Modeling Transitions in Human Emotions. International Robotics and Automation Journal 3(2): 00049

Shapiro, B. (2013). Porn Generation: How Social Liberalism is Corrupting our Future. Regnery Publishing.

Smith, C. and Attwood, F. (2012). Emotional Truths and Thrilling Slide Shows: The Resurgence of Antiporn Feminism. In Taormino, T., Parrenas Shimizu, C., Penley, C., Miller-Young, M. (2013). The Feminist Porn Book: The Politics of Producing Pleasure. New York: The Feminist Press at CUNY.

Sparrow, R. (2017). Robots, Rape and Representation. Journal of Social Robotics 9(4): 465-477

Tankard-Reist, M. and Bray, A. (eds) (2011). Big Porn Inc: Exposing the Harms of the Global Pornography Industry. North Melbourne, VIC: Spinifex Press.

Taormino, T., Parrenas Shimizu, C., Penley, C., Miller-Young, M. (2013). The Feminist Porn Book: The Politics of Producing Pleasure. New York: The Feminist Press at CUNY.

Weber, P. (2013). What, Exactly, is Feminist Porn? The Week 9 April 2013, available at http://theweek.com/articles/465779/what-exactly-feminist-porn 